Sokoto Journal of Medical Laboratory Science 2021; 6(4): 32 - 39

SJMLS - 6(4) - 004

\title{
Bone Biochemical Profile of Epileptic Patients Undergoing Anti-Epileptic Drug Therapy in Maiduguri, Nigeria
}

\author{
Mamza, Y.P., Gana, B.S., Gali, R.M., Musa, A.H., Medugu, J.T.*, Mohammed, U. \\ Department of Medical Laboratory Science, College of Medical Sciences University of Maiduguri, Nigeria \\ Author for Correspondence*: medugujessy@gmail.com \\ https://dx.doi.org/10.4314/sokjmls.v6i4.4
}

\begin{abstract}
Epilepsy is characterized by repeated seizure which is an excessive discharge or excitation of cerebral cortical neurons causing disturbance in sensation, loss of consciousness and impairment of mental function. This study was conducted to evaluate the bone biochemical parameters of Epileptic patients on Anti-epileptic drugs (AEDs) therapy. One hundred and thirty (130) subjects participated in the study which consist of 80 Epileptic patients on AEDs therapy and 50 were age matched controls. Serum calcium, serum Inorganic phosphate, serum Albumin, Serum Total Alkaline Phosphatase (ALP) and Bone-Specific Alkaline Phosphatase activity and Tartarate Resistance Acid Phosphatase (TRACP) Activity Estimation were determined using standard techniques. The mean value of Calcium was significantly $(p<0.05)$ lower in Epileptic patients as compared to that of controls $(1.93 \pm 0.40$ vs. $2.25 \pm 0.25 \mathrm{mmol} / \mathrm{L})$. While that of inorganic phosphatase was significantly $(\mathrm{p}<$ 0.05 ) higher in epileptic patients as compared to the controls $(1.40 \pm 0.62$ vs. $1.11 \pm 0.38$ $\mathrm{mmol} / \mathrm{L})$. No significant difference $(\mathrm{p}>0.05)$ was observed in Albumin, total and bone ALP activity and TRACP activity in Epileptic patients as compared to controls. Also, no significant difference $(p>0.05)$ was observed in the mean values of Calcium, Inorganic Phosphate, Albumin, Total ALP, Bone-specific ALP and TRACP activity of male and female Epileptic patients. Among the clinicians involved in the management of epileptic patients, $16(72.73 \%)$ were aware that AEDs predisposes Epileptic patients to Bone metabolic disorders. In conclusion, decreased calcium and elevated
\end{abstract}

phosphate were abnormal biochemical findings observed in the study indicating bone metabolic disorders which may lead to bone loss and increased risk of fracture in Epileptic patients on anti-epileptic drug therapy.

Keywords: Epileptic, Calcium, Inorganic phosphate, Albumin, ALP, TRACP

\section{Introduction}

Epilepsy is defined as a condition characterized by repeated occurrence of seizure which is an excessive discharge or excitation of cerebral cortical neurons resulting in disruption of consciousness, disturbance of sensation, impairment of mental function or combination of these signs accompanied by abnormal electroencephalogram (Thompson et al., 2005). Epilepsy is a common neurological disorder especially in the developed world where approximately 5-10 per 1000 are affected (Sanders, 2003). Electrical activity is constantly occurring in the brain at all time, seizure happens when there is sudden burst of intense electrical activity in the brain (Shorvon, 2005).

Epilepsy is not a single condition but multiple (NICE, 2016), this is because there are many different types of epilepsy which can start at different times for different people and different types of epilepsy can produce different signs and symptoms. Epilepsy may develop after a particular identifiable event (e.g. asphyxia, head injury, meningitis), in which case it is symptomatic epilepsy. It may develop without any identifiable cause, and then it is called idiopathic epilepsy (WHO, 2002). The excessive 
nerve cell discharge or excitation may remain in a small area of the brain (a localized lesion or focus) seizures or start immediately in the whole brain or spread from the small area (focus) to the whole brain and spinal cord giving rise to generalized seizures, not only does these discharges vary in site, but also in severity, and therefore a wide variation is seen in clinical presentations (WHO, 2002). About $40 \%$ of patients suffering from epileptic seizure have a genetic background that contributes to the etiology of the epilepsy (Gardiner, 2000). Epilepsy can therefore be triggered by some factors which may include; head injury, brain tumor, cerebrovascular disease and contributory factors such as genetic factors. Also, other precipitating factors may trigger re-occurrence of seizures e.g. hyperventilation, over-hydration, high fever, hormonal changes especially during menstrual period (WHO, 2002).

The treatment of epilepsy involves the use of drugs known as Anti-Epileptic Drugs (AEDs). AEDs are aimed to stop and/or reduce seizure occurrence, undesirable episodes and to manage and treat co-morbid conditions. In additions to the AEDs used which is the first-line treatment, surgery is sometimes used (Ryvlin, 2003), with approximately $60 \%$ of patients gaining control over seizure with surgery (Jacobs et al.,2009). The adverse effect of AEDs on bone health was first reported about four decades ago (Dent et al., 1970; Kruse, 1968). This is revealed by a variety of biochemical, metabolic and radiologic abnormalities in bone health (Ali et al., 2004; Pack et al., 2004; Sheth, 2004). Low bone density associated with AEDs usage is largely unrecognized, undetected and untreated (Pack et al., 2004; Sheth, 2004) and this has been shown to be an independent risk factor for low bone density and osteoporosis (Fulton, 1999).

Abnormal bone metabolism due to AEDs usage may result in a condition such as osteoporosis, osteomalacia/rickettsia. Subjects on these classes of drugs are however drug dependent, that is they may live for the rest of their lives on AEDs thus predisposing them to abnormal bone metabolism. This problem among other problems may cause a decrease in the quality of life and more complications at a later age in life.
It is in view of the above problems that this research work is being carried out.

\section{Materials and Methods}

All subjects recruited for this study were epileptic patients undergoing AEDs therapy at the Federal Neuropsychiatric Hospital, Maiduguri, Borno State. One hundred and thirty subjects were recruited for the study. They were differentiated into two groups; 80 were epileptic subjects and 50 non-epileptic individuals were monitored as controls. A verbal informed consent was sought from each subject that participated in the study. Ethical clearance was obtained from the federal Neuropsychiatric Hospital Research and Ethics Committee.

The study included epileptic patients undergoing AEDs administration at the Federal Neuropsychiatric Hospital (FNPH and excluded subjects with recent history of fracture, bone disease, liver disease, and those on calcium and/or phosphate dietary supplements. Simple random sampling technique was used to select the epileptic subjects.

Venous blood sample were collected into sterile plain vacuum tube (Vacutainer) by venipuncture procedure. The blood was separated by centrifuge at 4000 revolutions per minute for 5 minutes and the serum was transferred into a Cryovials and stored at $4^{\circ} \mathrm{c}$ for batch analysis. The serum was then used to estimate for Calcium, Inorganic Phosphate and alkaline phosphatase activity.

Serum Calcium was estimated by O-cresolphthaline complexone without deproteinisation Method as described by Barnett (Barnett et al., 1973). Serum Inorganic phosphate was determined by Phosphomolybdic Acid method as described by Henry (Henry, 1974). Serum Albumin was estimated by Bromo-cresol Green Binding Method (Daumas et al., 1971). Serum Total Alkaline Phosphatase and Serum Bone-Specific Alkaline Phosphatase activity were determined by Phenolphthalein Monophosphate (King and Armstrong method) as described by Babson et al. (1966) while Acid Phosphatase Activity Estimation was done by Kinetic Method as described by Hillman (Hillman, 1971). 
The data obtained from the study was analyzed using the Statistical Package for Social Sciences (SPSS) version 20.0 for windows. Student " $t$ " test was used to test for the differences between the means of the two groups. The level of significance was set at $95 \%$ confidence interval where $\mathrm{p}<0.05$ was considered as statistically significant.

\section{Results}

Eighty (80) epileptic subjects on AEDs were recruited in this study. Out of the 80 patients, $42(52.5 \%)$ are males and $38(47.5 \%)$ are females. Fifty apparently healthy persons were monitored as controls comprising of $27(54 \%)$ males and 23 $(46 \%)$ females. There was no significant difference $(p>0.05)$ between the mean age and BMI of epileptic patients and controls. Their duration of AEDs usage was $6.63 \pm 5.09$ years (Table 1). Sixty-three $(78.75 \%)$ patients were placed on carbamazepine, $3(3.75 \%)$ on Valproic acid, $13(16.75 \%)$ on polytherapy consisting of Carbamazepine and $1(1.25 \%)$ patient on other AEDs (Figure 1 and 2).
The mean value of serum Calcium was significantly $(p<0.05)$ lower among the Epileptic subjects compared to that of controls, while the mean serum inorganic phosphatase was significantly $(p<0.05)$ higher among the epileptic subjects compared to the controls (table 2). This study also showed no significant difference $(p>0.05)$ in the mean of serum calcium, inorganic phosphate, total and bone-specific ALP activity and TRACP activity between male and female epileptic patients (table 3). Table 4 shows the survey carried out in this study to assess the level of awareness among Clinicians on the effect of AEDs on bone metabolism and the study included 22 healthcare workers consisting of 18 Neuropsychiatric Doctors and 4 Pharmacist at the Federal Neuro-Psychiatric Hospital Maiduguri. Findings indicated that $16(72.73 \%)$ of the healthcare workers (14 Doctors and 2 Pharmacists) were aware that AEDs usage is associated with bone metabolic disorders and may result in bone loss and subsequently fracture. Despite this high level of awareness, none $(0 \%)$ administer prophylactic calcium and vitamin $\mathrm{D}$ to patients on AEDs.

Table1: Anthropometric Data of Epileptic and Control Subjects

\begin{tabular}{|c|c|c|c|c|}
\hline Parameters & Epileptic Patients $(n=80)$ & $\begin{array}{l}\text { Controls } \\
(n=50)\end{array}$ & P-Value & Remark \\
\hline Age (Years) & $29.94 \pm 13.50$ & $25.88 \pm 13.14$ & 0.093 & NS \\
\hline Male & $42(52.5 \%)$ & $27(54 \%)$ & - & - \\
\hline \multicolumn{5}{|l|}{ Gender } \\
\hline Female & $38(47.5 \%)$ & $23(46 \%)$ & & \\
\hline & & & - & - \\
\hline $\begin{array}{l}\text { Body } M \text { ass Index } \\
\left(\mathrm{Kg} / \mathrm{m}^{2}\right)\end{array}$ & $20.86 \pm 3.49$ & $21.75 \pm 5.62$ & 0.316 & NS \\
\hline $\begin{array}{l}\text { Age of Disorder } \\
\text { (Years) }\end{array}$ & $18.21 \pm 12.33$ & - & - & - \\
\hline $\begin{array}{l}\text { Duration of } \\
\text { AEDs Usage (Years) }\end{array}$ & $6.63 \pm 5.09$ & - & - & - \\
\hline
\end{tabular}

Key: Values of Ages and BMI are expressed as Mean \pm Standard Deviation NS- Not Significant 


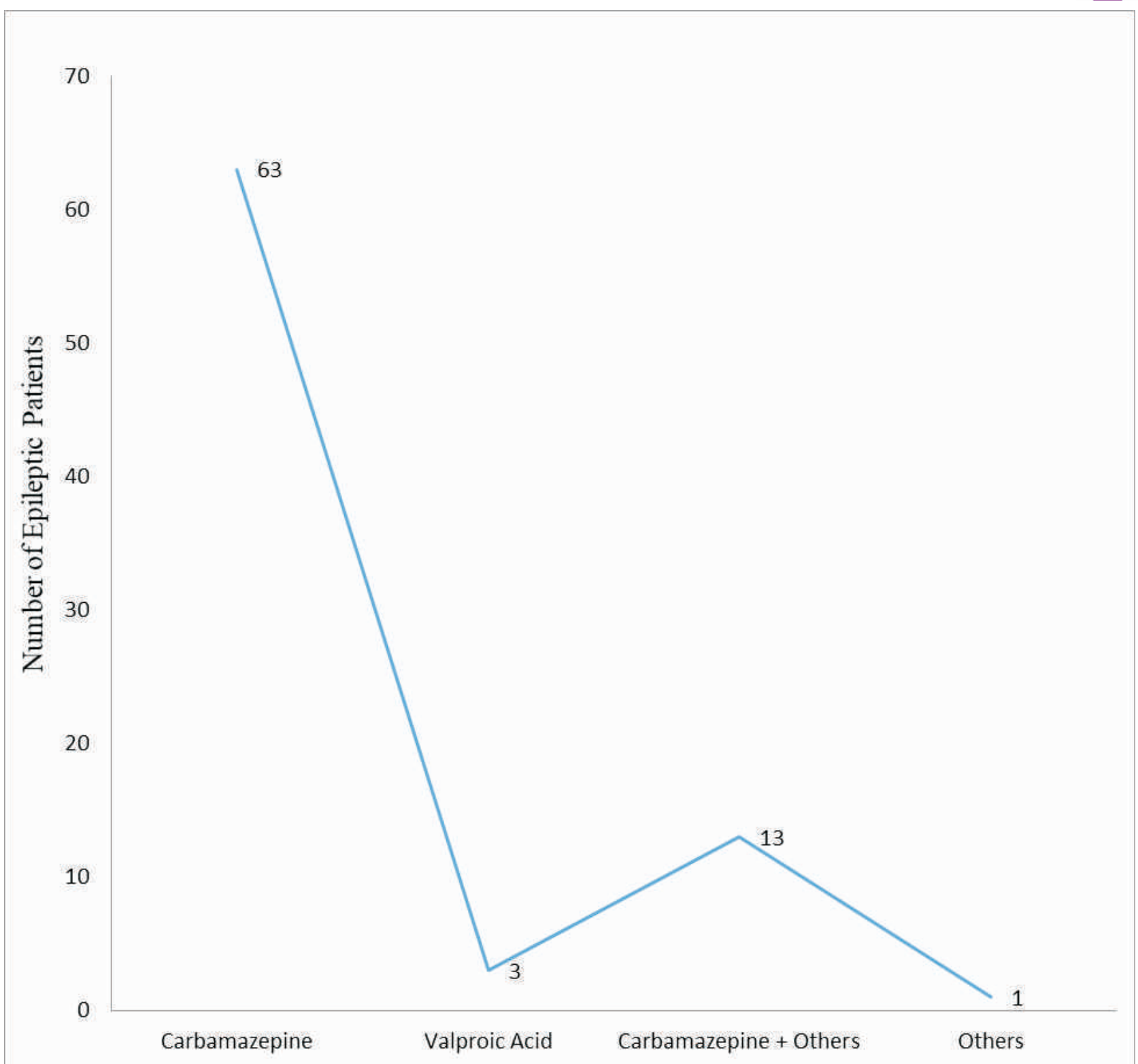

Anti-epileptic Drug Type

Figure 1: Distribution of Drug Type Commonly used by Epileptic Patients in Maiduguri 


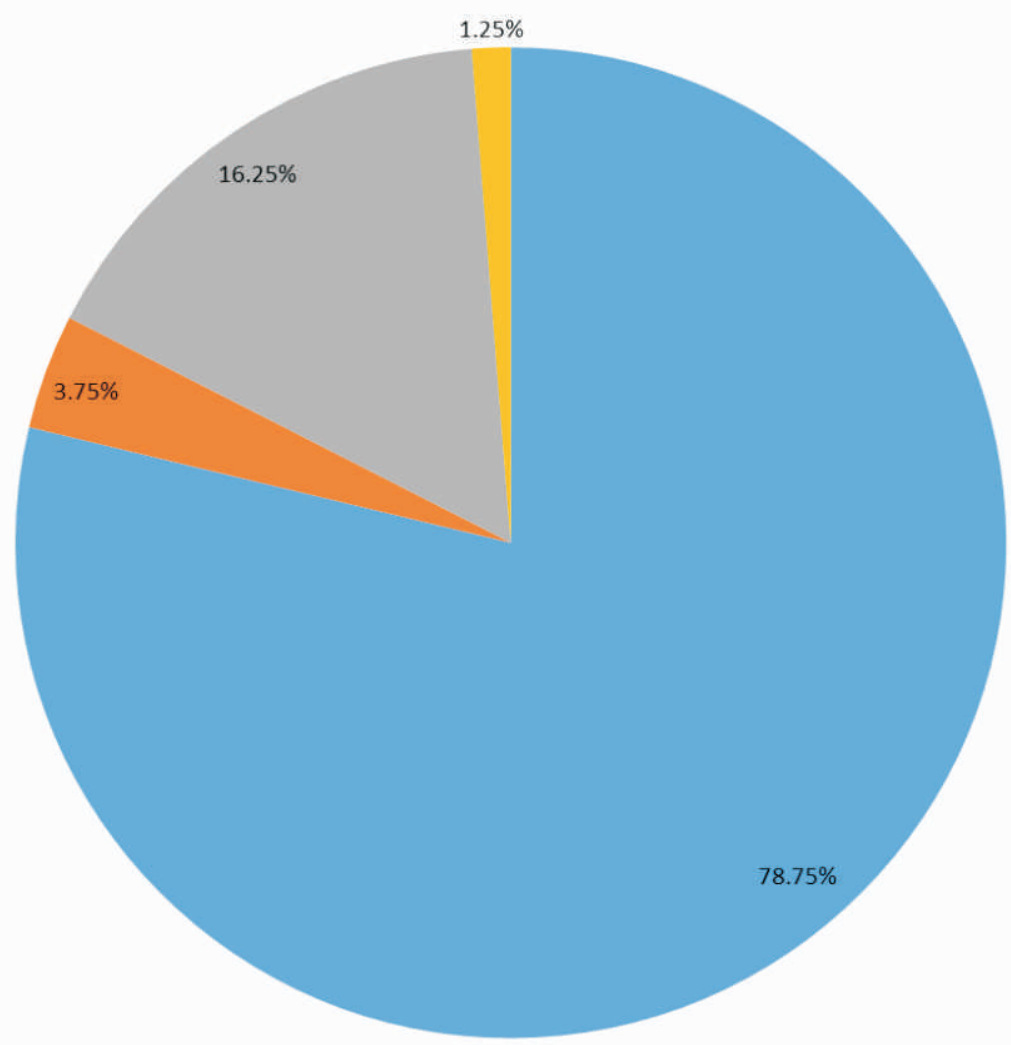

Figure 2: Drug Types used by Epileptic Patients in Maiduguri

Table 2: Comparison of Mean of Serum Biochemical Parameters between Epileptic and Control Subjects

\begin{tabular}{|c|c|c|c|c|c|}
\hline $\begin{array}{l}\text { Biochemical } \\
\text { Parameters }\end{array}$ & $\begin{array}{l}\text { Epileptic } \\
\text { subjects }(n=80)\end{array}$ & $\begin{array}{l}\text { Control } \\
\text { subjects } \\
n=50\end{array}$ & t-value & P-value & Remark \\
\hline $\begin{array}{l}\text { Serum Calcium } \\
(\mathrm{mmol} / \mathrm{L})\end{array}$ & $1.93 \pm 0.40$ & $2.25 \pm 0.25$ & 5.57 & 0.000 & $\mathrm{~S}$ \\
\hline Serum Albumin $(\mathrm{g} / \mathrm{L})$ & $40.76 \pm 5.11$ & $41.86 \pm 3.00$ & 1.54 & 0.126 & NS \\
\hline $\begin{array}{l}\text { Inorganic } \\
\text { Phosphate(mmol/L) }\end{array}$ & $1.40 \pm 0.62$ & $1.11 \pm 0.38$ & -3.26 & 0.001 & S \\
\hline $\begin{array}{l}\text { Bone-specific ALP } \\
(\mathrm{IU} / \mathrm{L})\end{array}$ & $14.33 \pm 9.62$ & $15.94 \pm 14.05$ & 0.714 & 0.477 & NS \\
\hline Total ALP (IU/L) & $38.06 \pm 24.86$ & $34.90 \pm 16.72$ & -0.867 & 0.388 & NS \\
\hline TRACP (IU/L) & $4.85 \pm 2.10$ & $4.68 \pm 2.32$ & -0.405 & 0.687 & NS \\
\hline
\end{tabular}

Key: Values are expressed as Mean $\pm S D, S=$ Significant, $N S=$ Not significant 
Table 3: Comparison of the Mean of Biochemical Parameters between Male and Females Epileptic Subjects

\begin{tabular}{llllll}
\hline Biochemical Parameters & Male $(\mathbf{n}=\mathbf{4 2})$ & Female $(\mathbf{n}=\mathbf{3 8})$ & t-value & P-value & Remark \\
\hline Serum Calcium (mmol/L) & $1.95 \pm 0.44$ & $1.91 \pm 0.36$ & 0.495 & 0.622 & NS \\
Serum Albumin (g/L) & $40.93 \pm 4.03$ & $40.58 \pm 6.14$ & 0.298 & 0.767 & NS \\
$\begin{array}{l}\text { Serum Inorganic Phosphate } \\
(\mathrm{mmol} / \mathrm{L})\end{array}$ & $1.45 \pm 0.71$ & $1.34 \pm 0.50$ & 0.779 & 0.438 & $\mathrm{NS}$ \\
$\begin{array}{l}\text { Bone-specific ALP (IU/L) } \\
\text { Total ALP (IU/L) }\end{array}$ & $13.85 \pm 11.92$ & $14.85 \pm 6.30$ & -0.473 & 0.638 & $\mathrm{NS}$ \\
TRACP (IU/L) & $38.96 \pm 32.35$ & $37.07 \pm 15.11$ & 0.350 & 0.727 & $\mathrm{NS}$ \\
\hline
\end{tabular}

Key: Values are expressed as Mean $\pm S D, N S=$ Not significant

Table 4: Evaluation of Awareness among Clinicians on Side Effects of AEDs Therapy

\begin{tabular}{llll}
\hline Side Effects & Aw are (Percent) & Not aware (Percent) & Total (Percent) \\
\hline $\begin{array}{l}\text { Abnormal Lipid } \\
\text { Metabolism }\end{array}$ & $17(77.27 \%)$ & $5(22.73 \%)$ & $22(100 \%)$ \\
Hepatotoxicity & $22(100 \%)$ & $0(0 \%)$ & $22(100 \%)$ \\
Renal Toxicity & $20(90.91 \%)$ & $2(9.09 \%)$ & $22(100 \%)$ \\
Bone Metabolic & $16(72.73 \%)$ & $6(27.27 \%)$ & $22(100 \%)$ \\
$\begin{array}{l}\text { Disorders } \\
\text { Others }\end{array}$ & $9(40.91 \%)$ & $13(59.09 \%)$ & $22(100 \%)$ \\
\hline
\end{tabular}

\section{Discussion}

The therapy of Epilepsy using Anti-Epileptic drugs (AEDs) predisposes individuals to bone loss and increases their risk of having fractures (Cummings et al.,1995) and hospitalizations (Desai et al.,1996). Different AEDs have various biochemical presentations regarding bone metabolism. Despite these varying mechanisms of bone loss, they are still associated with abnormal bone biochemical parameters. There have been a number of studies trying to ascertain the relationship between AEDs usage and bone loss, but despite such efforts, there have been very little understanding regarding the exact mechanism of bone loss, even though different AEDs have different postulated relationship regarding this issue. Although in this study, majority of the AEDs used was Carbamazepine. In this work, we observed that the mean serum calcium concentration was significantly lower in the epileptic subjects on AEDs when compared with the control group. This finding is in agreement with previous reports by Pascussi etal. (2005) and Holick (2005). Calcium is an important bone mineral constituent $\left[\mathrm{Ca}_{10}\left(\mathrm{PO}_{4}\right)_{6}(\mathrm{OH})_{2}{ }^{-}\right.$Hydroxyapatite] which is essential in the mineralization and calcification of bone matrix into a tough and rigid tissue. Decreased plasma calcium level as seen in epileptic patients on AEDs means that is decreased or an ineffective bone mineralization despite normal bone formation. The overall bone matrix will not be fully calcified and thus becomes fragile and brittle. This can predispose them to fracture due to formation of bone tissues that are brittle and fragile. The percentage of hypocalcaemia $(72.5 \%)$ observed from this study therefore shows a positive relationship between AEDs usage and bone fragility, bone loss and ultimately fracture. This finding is also similar to earlier reports (Ali et al., 2004; Hamed et al., 2014; Pack et al., 2004; Pack and Morrell, 2004); Sheth, 2004) on the adverse effects of AEDs on bone health due to hypocalcaemia observed in the patients on AEDs. The pathophysiology of hypocalcaemia observed in 
these patients can be due to impaired intestinal absorption and/or increased renal clearance of calcium as a side effect of inactivation of vitamin D.

There was no significant difference in the mean serum albumin of Epileptic subjects and the the non-epileptic controls. This however signifies that the carrying capacity of Serum calcium is adequate and that the transport/carriage system is effective. There was also no significant difference in the serum albumin concentration based on the gender of epileptic subjects.

We also observed that the mean serum inorganic phosphate concentration was significantly higher in epileptic patients on AEDs when compared to the control group. This finding is contrary to earlier reports. Inorganic phosphate is an important component of hydroxyapatite; the mineral phase of the bone. Though phosphate is required for the bone strength, effective mineralization and calcification requires normal serum calcium concentration. Elevated serum inorganic phosphate can be as a result of increased renal reclamation of phosphate (elevated phosphate retention).

This study showed that there was no significant difference between the mean Serum bonespecific ALP and Serum total ALP activities with that of the control group. The finding is contrary to the report by Verroti et al. (2010) which indicated that there was an increased/elevated bone-specific ALP activity.

There was also no significant difference in the mean of serum tartrate resistant acid phosphatase activity of epileptic patients and controls. This finding is contrary to the report by Menon and Harinarayan (2010) who observed a decrease in the serum activity of TRACP activity. This normal level of serum TRACP activity indicates normal bone resorption.

From ours study, majority of patients are on AEDs, that is $78.75 \%$ of the patients are on Carbamazepine, which has been found to be a potent inducer of the Cytochrome P450 enzyme; CYP3A4.

We investigated the level of awareness among clinicians on the relationship between AEDs and bone loss. A significant 16(72.73\%) out of 22 clinicians were aware that AEDs therapy is associated with bone metabolic disorder and can result in bone loss. This finding is higher than the report by Valmadrid et al. (2001). However, none $(0 \%)$ of these clinicians prescribe prophylactic calcium and vitamin $\mathrm{D}$.

Due to the nature of therapy with anticonvulsant, routine monitoring of bone metabolic parameters is important in the early detection and follow-up of patients with identified risk of bone loss due to AEDs usage. Routine checkup of serum calcium, phosphate, ALP activity, TRACP activity, will be of enormous importance in monitoring therapy, to reduce the risk of other complication of AEDs and ascertaining the extent and effect of AEDs on bone metabolism.

\section{Acknowledgment}

We are grateful to the Department of Chemical Pathology Laboratory, University of Maiduguri Teaching Hospital for providing us with facilities used for our analysis. We also want to appreciate the Chief Medical Director Neuropsychiatric Hospital Maiduguri for allowing us to collect samples from their patients.

\section{Financial support and sponsorship: Nil \\ Conflicts of interest: There are no conflicts of interest}

\section{References}

Ali, L.L., Schuh, L., Barkley, G.L. \& Gates, J.R. (2004) Antiepileptic drugs and reduced bone mineral density. Epilepsy Behavior; 5:296300.

Babson, L.A., Greeley, S.J., Coleman, C.M. and Phillips, G.D. (1966). Phenolphthalein monophosphate as a substrate for serum alkaline phosphatase. Clinical Chemistry;12: 482-490.

Barnett, R.N., Sokodon, S.B., and Goldberg, M.H. (1973). Performance kit used for clinical Chemical analysis of calcium in serum. American Journal of Clinical Pathology; 59:836-843.

Cummings, S.R., Nevitt, M.C., Browner, W.S., Stone, K., Fox, K.M., Ensrud, K.E., Cauley, J., Black, D. \& Vogt, T.M. Risk factors for hip fracture in white women. Study of osteoporotic fractures Research Group. $N$ Engl JMed, 1995, 332, 767-773

Daumas, B.T., Watson, W.A. \& Biggs, H.G. (1971). Amino acids. Journal of Clinical Chemistry Acta; 31: 87. 
Dent, C.E., Richens, A., Rowe, D.J. \& Stamp, T.C. (1970). Osteomalacia with long-term anticonvulsant therapy in epilepsy. British Medical Journal; 4: 69-72.

Desai, K.B., Ribbans, W.J. \& Taylor G.J. (1996). Incidence of five common fracture types in an institutional epileptic population. Injury; 27: 97-100.

Fulton, I.P. (1999). New Guidelines for the Prevention and Treatment of Osteoporosis. National Osteoporosis Foundation Medicine and Health; 81:110-111.

Gardiner, R.M. (2000). Impact of our Understanding of the Genetic etiology of Epilepsy. Journal of Neurology; 247: 327-334

Hamed, S.A., Moussa, E.M.M., Youssef, A.H., AbdulElHamed, M.A. \& NasrEldin, E. (2014). Bone status in patients with epilepsy: Relationship to markers of bone remodeling. Frontiers in Neurology; 5:142-149.

Henry, R.J., Cannon, D.C. and Winkelman, J.W. (1974). "Clinical Chemistry: Principles and Techniques," 11th Edition, Happer and Row Publishers, New York, 1974, p. 1629.

Hillman, G.Z. (1971). Acid Phosphatase. Clinical Chemistryand Klin. Biochemistry; 3:273.

Holick, M.F. (2005). Stay tuned to PXR: an orphan actor that may not be Destructive only to bone. Journal of Clinical Investigation; 115: 32-34.

Jacobs, M., Lebland, P., Gabrielle, G., BrooksKayal, Amy, Jensen, Frances, E., Lowenstein Dan, H., Noebels, Jeffrey, L., Spencer, Dennis, D. and Swann, J.W. (2009). "Curing epilepsy: Progress and Future directions". Epilepsy \& Behavior; 14: 438-445.

Kruse, R. (1968). Osteopathies in antiepileptic long-term therapy (preliminary report). Monatsschr Kinderheilkd; 116: 378-381.

Menon, B. \& Harinarayan, C.V. (2010). The effect of Anti-epileptic drug therapy on serum 25-hydroxyvitamin D and parameters of calcium and bone metabolism- A longitudinal study. Seizure; 19(3):153-158.

NICE (2016). Diagnosis and Management of the epilepsies. Available at; http://www.nice. org.uk/nicemedia/live/13635/57779. pdf,2013, p. 20 (Accessed on December 19,2016).

Pack, A.M., Gidal, B. \& Vazquez, B. (2004). Bone disease associated with antiepileptic drugs. Cleve Clinical Journal of Medicine; 71(S2): S42-48.

Pack, A.M. \& Morrell, M.J. (2004). Epilepsy and bone Health in Adults. Epilepsy Behaviour; 5(S2): S24-29.

Pascussi, J.M., Robert, A., Nguyen, M., WalrantDebray, O., Garabedian, M., Martin, P., Pineau, T., Saric, J., Navrro, F., Maurel, P. \&Vilarem, M.J. (2005). Possible involvement of Pregame $X$ receptorenhanced CYP24 expression in druginduced osteomalacia. Journal of Clinical Investigation; 115: 177-186.

Ryvlin, P. (2003). Beyond Pharmacotherapy: Surgical Management". Epilepsia; 44(5): 23-28.

Sanders, J.W. (2005). The epidemiology of epilepsy revisited. Current Opinion in Neurology;16: 165-170.

Sheth, R.D. (2004). Metabolic concerns associated with antiepileptic medications. Neurology;63: S24-29.

Shorvon, S. (2005). Clinical forms and causes of epilepsy in: Shorvon, S. Handbook of Epilepsy Treatment, $2^{\text {nd }}$ edition. Oxford: Blackwell Publishing Ltd, 2005.

Thompson, N., Osorio, C.I., Hunter, E.E. (2005). "Non-epileptic seizures: Reframing the diagnostic Perspective in Psychiatric Care; 41(2): 71-78.

Valmadrid, C., Voorhees, C., Litt, B. \& Schneyer, C.R. (2001). Practice patterns of Neurologists regarding bone and mineral effects of antiepileptic drug therapy. Archives of Neurology; 58: 1369-1374.

Verrotti, A., Coppola, G., Parisi, P., Mohn, A. \& Chiarelli, F. (2010). Bone and calcium metabolism and antiepileptic drugs. Clinical Neurology and Neurosurgery; 112: 1-10.

WHO (2000). Epilepsy; A Manual for Medical and Clinical Officers in Africa. Revised Edition,2002.

Citation: Mamza, Y.P., Gana, B.S., Gali, R.M., Musa, A.H., Medugu, J.T.*, Mohammed, U. Sokoto Journal of Medical Laboratory Science; 6(4): 32 - 39.

Copyright. This is an open-access article distributed under the terms of the Creative Commons Attribution License, which permits unrestricted use, distribution, and reproduction in any medium, provided the original author and source are credited. 